\title{
Maternal occupational exposure and oral clefts in offspring
}

\author{
Nynke Spinder ${ }^{1,2^{*}}$ (D) Jorieke E. H. Bergman², H. Marike Boezen ${ }^{1}$, Roel C. H. Vermeulen ${ }^{3}$, Hans Kromhout ${ }^{3}$ \\ and Hermien E. K. de Walle
}

\begin{abstract}
Background: Previous studies suggest that periconceptional maternal occupational exposure to solvents and pesticides increase the risk of oral clefts in the offspring. Less is known about the effect of occupational exposure to metals, dust, and gases and fumes on development of oral clefts.

Methods: This case-malformed control study used data from a population-based birth defects registry (Eurocat) of children and foetuses born in the Northern Netherlands between 1997 and 2013. Cases were defined as nonsyndromic oral clefts. The first control group had chromosomal/monogenic defects, and the second control group was defined as non-chromosomal/non-monogenic malformed controls. Maternal occupational exposure was estimated through linkage of mothers' occupation with a community-based Job Exposure Matrix (JEM). Multivariate logistic regression was used to estimate the effect of occupational exposures. Odds ratios were adjusted (aORs) for relevant confounders.
\end{abstract}

Results: A total of 387 cases, 1135 chromosomal and 4352 non-chromosomal malformed controls were included in this study. Prevalence of maternal occupational exposures to all agents was $43.9 \%$ and $41.0 \% / 37.7 \%$ among cases and controls, respectively. Oral clefts had significantly increased ORs of maternal occupational exposure to pesticides ( $\mathrm{aOR}=1.7,95 \%$ confidence interval $[\mathrm{Cl}] 1.0-3.1)$ and dust $(\mathrm{aOR}=1.3,95 \% \mathrm{Cl} 1.1-1.6)$ when using nonchromosomal controls. Subgroup analysis for $\mathrm{CL}(\mathrm{P})$ stratified by gender showed a significantly increased risk for male infants exposed to 'other solvents' and exposure to mineral dust for female infants.

Conclusion: Our study showed that maternal occupational exposure to pesticides and dust are risk factors for oral clefts in the offspring. Larger studies are needed to confirm this finding.

Keywords: Biological dust, Congenital anomalies, Job-exposure matrix, Metals, Mineral dust, Occupational exposure, Pesticides, Solvents, Teratology

\section{Background}

Oral clefts are one of the most common congenital anomalies in the Netherlands with a prevalence of 2.1 per 1000 live births [1]. Oral clefts are complex malformations that result from failure of fusion of the lip or palate. Because of different developmental origins, oral clefts can be classified as cleft palate $(\mathrm{CP})$ or cleft lip with or without palate $(\mathrm{CL}(\mathrm{P}))$. Oral clefts have a large

\footnotetext{
* Correspondence: n.spinder@umcg.nl

'Department of Epidemiology, University of Groningen, University Medical Center Groningen, HPC FA 40, P.O. Box 30.001, 9700 RB Groningen, the Netherlands

${ }^{2}$ Department of Genetics, University of Groningen, University Medical Center Groningen, HPC CB 51, P.O. Box 30.001, 9700 RB Groningen, the Netherlands Full list of author information is available at the end of the article
}

impact on the affected individuals, their parents and on the community in terms of physical and emotional wellbeing, and medical costs [2]. The etiology of oral clefts is not fully understood, but involves genetic as well as environmental factors. Several environmental factors during pregnancy have been associated with an increased risk of oral clefts in the offspring, including maternal smoking [3], maternal alcohol consumption [4] and high maternal pre-pregnancy body mass index (BMI) $\left(>30 \mathrm{~kg} / \mathrm{m}^{2}\right)$ [5-7]. There is no consensus on whether folic acid is protective or might be a risk factor for oral clefts [8].

Participation of Dutch women in the labour market has increased substantially over the last two decades [9]. 
Therefore, it is important to examine exposure to various teratogenic factors in the workplace. Large population based case-control studies suggest a relationship between exposure to organic solvents and oral clefts [10-17], whereas one other study did not find a higher risk of oral clefts in the offspring after maternal occupational exposure to solvents [18].

Several studies have investigated maternal occupational exposure to pesticides and risk of oral clefts in the offspring. Romitti et al. performed a meta-analysis and concluded that maternal exposure to pesticides in general is associated with a small increased risk of oral clefts in the offspring [19]. More recently, Yang et al. assessed residential exposure to specific agricultural pesticides in an area with high rates of pesticide use and concluded that there was a positive relationship between herbicide exposure and oral clefts, especially among female infants [20].

There is one previous study that suggested an association between maternal occupational exposure to metals and oral clefts in the offspring [21]. As far as we know, there is no literature concerning occupational exposure to mineral and organic dust, and gases and fumes in relation to the occurrence of oral clefts. However, since these exposures often occur in the same workplace as exposure to solvents and pesticides, these exposures were also taken into account in this study.

The objective of this case-malformed control study was to examine the association between maternal occupational exposure to, in particular solvents and pesticides, but also to metals, mineral and organic dusts, and gases and fumes during the periconceptional period and risk of oral clefts in the offspring.

\section{Methods}

\section{Study design and population}

To examine the possible association between maternal occupational exposure and oral clefts in the offspring a case-malformed control study was performed. Cases and malformed controls were selected from the European Registration of Congenital Anomalies and Twins database of the Northern Netherlands (Eurocat NNL). This population-based registry has been monitoring congenital anomalies in about 18,000 births annually in the provinces of Groningen, Friesland and Drenthe since 1981. In addition to live births (up to 10 years of age at notification), stillbirths, miscarriages and terminated pregnancies because of a congenital anomaly, are registered in the database. Children and foetuses are only registered in Eurocat NNL after parents give informed consent. In general, the informed consent rate is around $80 \%$ for all types of congenital anomalies.

Coding and classification of congenital anomalies are performed according to Eurocat guidelines [22]. In this study, Eurocat NNL data of children and foetuses born from 1997 until 2013 was used.

\section{Data collection}

Since 1997, parents have been asked to complete a written questionnaire to supply information about the pregnancy. The questionnaire includes a question about maternal occupation and the workplace (e.g. the company where the mother worked) at the beginning of the pregnancy. In addition, information is gathered concerning medical history, demographic characteristics and maternal pre-pregnancy weight and height. For smoking habits, alcohol consumption, and the use of medication, information is gathered from three months before pregnancy until the end of pregnancy. After parental consent, data on prescribed medication is retrieved from the pharmacy. Ambiguities in the questionnaire, actual use of medication and for which period it was used, were verified in a telephone interview with the mother.

\section{Definition of cases and controls}

Cases were defined as non-syndromic clefts, either occurring isolated or together with other major congenital anomalies. Children with a Pierre Robin sequence were included in the case group. International Classification of Diseases 9th revision (ICD-9, 749) was used for births up until 2001 and the ICD-10 classification (Q35-Q37) was used for births since 2002. A total of 679 cases with an oral cleft were selected for this study. Cases with a cleft that were also labelled as having a chromosomal or monogenic disorder were excluded $(n=89)$, because these clefts may be part of that specific syndrome. Additionally, cases with anencephaly, arhinencephaly and holoprosencephaly were excluded $(n=9)$ because these anomalies are often associated with oral clefts. In total, 95 cases $(14 \%)$ were excluded because mothers' occupation was unknown (e.g. the questionnaire was not returned). In this study only mothers with a paid job were included, which led to an exclusion of 99 cases (e.g. housewives).

Non-malformed children are not registered in the Eurocat database. Infants and foetuses born with chromosomal/monogenic disorders, not accompanied by oral clefts, were used as controls, because the etiology of these malformations is known. In total, 1764 chromosomal controls were selected for this study. We excluded 357 controls (20\%) because mothers' occupation was unknown and another 272 controls were excluded because their mothers had no paid job. Hereafter we refer to this group as chromosomal controls.

Analyses were performed with a second control group, because chromosomal controls can introduce bias through higher maternal age. This second control group is defined as all other babies/foetuses registered in 
Eurocat with non-chromosomal/non-monogenic disorders, and no malformation accompanied by an oral cleft. A total of 6847 babies/foetuses were selected for the non-chromosomal malformed control group. Because mothers' occupation was unknown, 1626 controls (24\%) were excluded. Furthermore, 869 controls were excluded because mother had no paid job. Hereafter we refer to this group as non-chromosomal controls.

This resulted in a total of 387 cases, 1135 chromosomal controls and 4352 non-chromosomal controls. Cases were further subdivided in a group of $\mathrm{CP}$ $(n=124)$ and a group of $\mathrm{CL}(\mathrm{P})(n=263)$.

\section{Exposure assessment}

A community-based JEM (ALOHA+ JEM) is applied to translate self-reported information about mothers' occupation during the periconceptional period (three months before conception through the first trimester) into occupational exposures to solvents, pesticides, metals and more generic categories like mineral and organic dust, and gases and fumes. The ALOHA+ JEM is built specifically for use in community-based studies [23]. Given that specific occupational exposures are relatively rare in the general population, specificity in exposure assignment was preferred over sensitivity when elaborating the ALOHA+ JEM [24].

Jobs were coded by two of the authors (NS and HK) into the International Standard Classification of Occupations 1988 (ISCO88) without knowledge of case/control status [25]. The ALOHA+ JEM assigned occupational exposure to solvents (aromatic, chlorinated and other [e.g. alkanes, alcohols, and esters]), pesticides (fungicides, herbicides and insecticides), metals, dust (organic and mineral), and gases and fumes. Based on the mothers' occupation, the JEM assigned no (0), low (1) or high (2) exposure to solvents, pesticides, metals, dust, and gases and fumes. For mothers who had two or more jobs with different exposures, the highest exposure category was selected.

\section{Variable definition}

Potential confounders applied in our analyses were child sex (boy or girl), number of babies/foetuses delivered (1 or $\geq 2)$, previous births ( 0,1 or $\geq 2$ births), maternal age at delivery $(15-19,20-24,25-29,30-39, \geq 40$ years old), maternal BMI (underweight $\left[<18.5 \mathrm{~kg} / \mathrm{m}^{2}\right]$, normal [18.5-25 $\left.\mathrm{kg} / \mathrm{m}^{2}\right]$, overweight $\left[25-30 \mathrm{~kg} / \mathrm{m}^{2}\right]$, obese $\left[>30 \mathrm{~kg} / \mathrm{m}^{2}\right]$ ), maternal education level (low [primary school, lower vocational education, pre-vocational education], middle [secondary vocational education, general secondary education or pre-university education] or high [higher professional education or academic education]), maternal smoking (no, yes/some period during pregnancy), maternal alcohol use during pregnancy (no, yes/ some period during pregnancy), folic acid use (no/wrong period, yes/periconceptional period [400 $\mu \mathrm{g}$ folic acid/ day from 4 weeks before until 8 weeks after conception [26]), fertility problems (no, yes [self-reported fertility problems or fertility treatment]) and positive family history (yes/no). A positive family history means a firstdegree family member with the same condition as the baby/foetus under study, e.g. if a child has an oral cleft, the family history is positive when a first degree family member has an oral cleft as well.

\section{Statistical analyses}

The associations between specific maternal occupational exposures and oral clefts were assessed using univariate and multivariate logistic regression models to estimate crude odds ratios (OR) and adjusted ORs. We adjusted multivariate models for potential confounders, based on significance using Chi Square tests. Confounders for the analyses with chromosomal controls were child sex, maternal age at delivery, pre-pregnancy BMI, education level, smoking and alcohol use during pregnancy, and family history. Analyses with non-chromosomal controls were corrected for child sex and previous births as confounders. Separate subgroup analyses were conducted for $\mathrm{CP}$ and $\mathrm{CL}(\mathrm{P})$ alone compared with both control groups.

From literature is known that the prevalence of $\mathrm{CL}(\mathrm{P})$ is higher among male infants. Therefore, an additional analysis was performed stratified by child's gender. Due to the small number of mothers with high exposure, low and high exposure were merged into one 'any exposure' group for all types of occupational exposures. Additionally, for specific exposure categories with a high prevalence of exposed cases, it was possible to evaluate no, low, and high exposure categories separately. $P$-values of $<0.05$ were considered statistically significant. Statistical Package for the Social Sciences version 22 (SPSS V22) was used to perform all analyses.

\section{Results}

The baseline characteristics of 387 cases, 1135 chromosomal controls and 4352 non-chromosomal controls are presented in Table 1. Among cases there was a significant excess of males compared to chromosomal controls. Case mothers had a younger age at delivery, a higher BMI and their education level was lower. Furthermore, they smoked more often, used alcohol less often, and had less often a positive family history. The significant differences in baseline characteristics between oral clefts and chromosomal controls apply as well when $\mathrm{CL}(\mathrm{P})$ and chromosomal controls were compared, except for pre-pregnancy BMI. There were no significant differences in baseline characteristics between $\mathrm{CP}$ and chromosomal controls. 
Table 1 Baseline characteristics of cases (all oral clefts, cleft palate (CP), cleft lip with/without cleft palate CL(P)) compared with two malformed control groups

\begin{tabular}{|c|c|c|c|c|c|c|c|c|c|c|c|c|c|c|c|c|}
\hline & \multicolumn{2}{|c|}{$\begin{array}{l}\text { Chromosomal } \\
\text { controls }^{a}\end{array}$} & \multicolumn{2}{|c|}{$\begin{array}{l}\text { Non- } \\
\text { chromosomal } \\
\text { controls }\end{array}$} & \multicolumn{4}{|c|}{ All oral cleft } & \multicolumn{4}{|l|}{$C P$} & \multicolumn{4}{|c|}{$\mathrm{CL}(\mathrm{P})$} \\
\hline & $\mathrm{n}$ & $\%$ & $n$ & $\%$ & $n$ & $\%$ & $\begin{array}{l}p^{-} \\
\text {value }^{c}\end{array}$ & $\begin{array}{l}p^{-} \\
\text {value }^{d}\end{array}$ & $n$ & $\%$ & $\begin{array}{l}p^{-} \\
\text {value }^{c}\end{array}$ & $\begin{array}{l}p^{-} \\
\text {value }^{d}\end{array}$ & $n$ & $\%$ & $\begin{array}{l}p^{-} \\
\text {value }^{c}\end{array}$ & $\begin{array}{l}p^{-} \\
\text {value }^{d}\end{array}$ \\
\hline & 1135 & & 4356 & & 387 & & & & 124 & & & & 263 & & & \\
\hline Child sex & & & & & & & $<0.001$ & 0.21 & & & 0.83 & 0.43 & & & $<0.001$ & 0.02 \\
\hline Boy & 547 & 48.2 & 2373 & 54.5 & 227 & 58.7 & & & 61 & 49.2 & & & 166 & 63.1 & & \\
\hline Girl & 588 & 51.8 & 1970 & 45.3 & 160 & 41.3 & & & 63 & 50.8 & & & 97 & 36.9 & & \\
\hline Unknown & 0 & & 9 & & 0 & & & & 0 & & & & 0 & & & \\
\hline $\begin{array}{l}\text { Number of babies/foetuses } \\
\text { delivered }\end{array}$ & & & & & & & 0.31 & 0.98 & & & 0.09 & 0.30 & & & 0.86 & 0.50 \\
\hline 1 & 1089 & 96.0 & 4104 & 94.8 & 366 & 94.8 & & & 115 & 92.7 & & & 251 & 95.8 & & \\
\hline$>1$ & 45 & 4.0 & 223 & 5.2 & 20 & 5.2 & & & 9 & 7.3 & & & 11 & 4.2 & & \\
\hline Unknown & 1 & & 25 & & 1 & & & & 0 & & & & 1 & & & \\
\hline Previous births & & & & & & & 0.24 & 0.01 & & & 0.60 & 0.11 & & & 0.36 & 0.05 \\
\hline 0 & 476 & 42.3 & 2313 & 53.2 & 180 & 46.6 & & & 57 & 46.0 & & & 123 & 46.9 & & \\
\hline 1 & 461 & 40.9 & 461 & 34.6 & 141 & 36.5 & & & 45 & 36.3 & & & 96 & 36.6 & & \\
\hline$\geq 2$ & 189 & 16.8 & 189 & 12.1 & 65 & 16.8 & & & 22 & 17.7 & & & 43 & 16.4 & & \\
\hline Unknown & 9 & & 8 & & 1 & & & & 0 & & & & 1 & & & \\
\hline Maternal age at delivery & & & & & & & $<0.001$ & 0.66 & & & 0.09 & 0.40 & & & $<0.001$ & 0.66 \\
\hline $15-19$ & 4 & 0.4 & 14 & 0.3 & 2 & 0.5 & & & 0 & & & & 2 & 0.8 & & \\
\hline $20-24$ & 55 & 4.8 & 369 & 8.5 & 24 & 6.2 & & & 8 & 6.5 & & & 16 & 6.1 & & \\
\hline $25-29$ & 299 & 26.3 & 1458 & 33.5 & 132 & 34.3 & & & 43 & 35.0 & & & 89 & 34.0 & & \\
\hline $30-34$ & 407 & 35.9 & 1770 & 40.7 & 154 & 40.0 & & & 47 & 38.2 & & & 107 & 40.8 & & \\
\hline $35-39$ & 284 & 25.0 & 651 & 15.0 & 63 & 16.4 & & & 19 & 15.4 & & & 44 & 16.8 & & \\
\hline$>40$ & 86 & 7.6 & 86 & 2.0 & 10 & 2.6 & & & 6 & 4.9 & & & 4 & 1.5 & & \\
\hline Unknown & 0 & & 0 & & 2 & & & & 1 & & & & 1 & & & \\
\hline Pre-pregnancy BMI (kg/m²) & & & & & & & 0.03 & 0.21 & & & 0.19 & 0.49 & & & 0.09 & 0.29 \\
\hline$<18.5$ & 30 & 2.8 & 112 & 2.7 & 12 & 3.2 & & & 2 & 1.7 & & & 10 & 3.9 & & \\
\hline $18.5-25$ & 721 & 66.3 & 2713 & 64.6 & 224 & 59.1 & & & 71 & 59.2 & & & 153 & 59.1 & & \\
\hline $25-30$ & 258 & 23.7 & 975 & 23.2 & 101 & 26.6 & & & 33 & 27.5 & & & 68 & 26.3 & & \\
\hline$>30$ & 78 & 7.2 & 402 & 9.6 & 42 & 11.1 & & & 14 & 11.7 & & & 28 & 10.8 & & \\
\hline Unknown & 48 & & 150 & & 8 & & & & 4 & & & & 4 & & & \\
\hline Education level & & & & & & & 0.01 & 0.84 & & & 0.59 & 0.72 & & & 0.01 & 0.56 \\
\hline Low & 151 & 13.8 & 545 & 12.8 & 51 & 13.5 & & & 15 & 12.4 & & & 36 & 14.0 & & \\
\hline Middle & 462 & 42.2 & 2137 & 50.3 & 193 & 51.1 & & & 57 & 47.1 & & & 136 & 52.9 & & \\
\hline High & 481 & 44.0 & 1568 & 36.9 & 134 & 35.4 & & & 49 & 40.5 & & & 85 & 33.1 & & \\
\hline Unknown & 41 & & 102 & & 9 & & & & 3 & & & & 6 & & & \\
\hline Smoking during pregnancy & & & & & & & 0.02 & 0.47 & & & 0.72 & 0.49 & & & 0.01 & 0.18 \\
\hline No & 89 & 81.0 & 3321 & 77.0 & 291 & 75.4 & & & 98 & 79.7 & & & 193 & 73.4 & & \\
\hline Yes & 210 & 19.0 & 992 & 23.0 & 95 & 24.6 & & & 25 & 20.3 & & & 70 & 26.6 & & \\
\hline Unknown & 28 & & 39 & & 1 & & & & 1 & & & & 0 & & & \\
\hline Alcohol during pregnancy & & & & & & & 0.02 & 0.16 & & & 0.25 & 0.62 & & & 0.03 & 0.17 \\
\hline No & 811 & 73.3 & 3276 & 76.1 & 306 & 79.3 & & & 96 & 78.0 & & & 210 & 79.8 & & \\
\hline
\end{tabular}


Table 1 Baseline characteristics of cases (all oral clefts, cleft palate (CP), cleft lip with/without cleft palate CL(P)) compared with two malformed control groups (Continued)

\begin{tabular}{|c|c|c|c|c|c|c|c|c|c|c|c|c|c|c|}
\hline Yes & 296 & 26.7 & 1029 & 23.9 & 80 & 20.7 & & & 27 & 22.0 & & 53 & 20.2 & \\
\hline Unknown & 28 & & 47 & & 1 & & & & 1 & & & 0 & & \\
\hline Folic acid use & & & & & & & 0.64 & 0.84 & & 0.67 & 0.52 & & 0.34 & 0.49 \\
\hline No & 224 & 21.3 & 844 & 20.5 & 77 & 20.1 & & & 28 & 23.0 & & 49 & 18.8 & \\
\hline Yes & 830 & 78.7 & 3265 & 79.5 & 306 & 79.9 & & & 94 & 77.0 & & 212 & 81.2 & \\
\hline Unknown & 81 & & 243 & & 4 & & & & 2 & & & 2 & & \\
\hline Fertility problems & & & & & & & 0.39 & 0.29 & & 0.73 & 0.11 & & 0.19 & 0.84 \\
\hline No & 889 & 81.0 & 3634 & 85.0 & 316 & 82.9 & & & 98 & 79.7 & & 218 & 84.5 & \\
\hline Yes & 209 & 19.0 & 643 & 15.0 & 65 & 17.1 & & & 25 & 20.3 & & 40 & 15.5 & \\
\hline Unknown & 37 & & 75 & & 6 & & & & 1 & & & 5 & & \\
\hline Positive family history ${ }^{e}$ & & & & & & & 0.003 & 0.08 & & 0.17 & 0.60 & & 0.005 & 0.07 \\
\hline No & 960 & 85.0 & 3819 & 88.0 & 352 & 91.0 & & & 111 & 89.5 & & 241 & 91.6 & \\
\hline Yes & 170 & 15.0 & 523 & 12.0 & 35 & 9.0 & & & 13 & 10.5 & & 22 & 8.4 & \\
\hline Unknown & 4 & & 10 & & 0 & & & & 0 & & & 0 & & \\
\hline
\end{tabular}

${ }^{a}$ chromosomal/monogenic controls (not accompanied with oral clefts), ${ }^{b}$ non-chromosomal/non-monogenic malformed controls (not accompanied with oral clefts), ${ }^{c} p$-value comparing cases with chromosomal controls, ${ }^{d} p$-value comparing cases with non-chromosomal controls, ${ }^{\mathrm{e}}$ positive family history when first degree family member has same condition as child under study. Bold values represent significant values $(p<0.05)$

None of these significant differences were observed when cases were compared with non-chromosomal controls, except the excess of males in the $\mathrm{CL}(\mathrm{P})$ group. Mothers with a child with an oral cleft had significantly more previous births.

The prevalence of estimated occupational exposure to any of the agents considered was $43.9 \%$ among case mothers, $41.0 \%$ among mothers of chromosomal controls (Table 2), and $37.7 \%$ among nonchromosomal controls (Table 3). Prevalence of maternal exposure to solvents was similar among cases and controls. The most frequent type of solvent exposure was exposure to 'other solvents'. Mothers exposed to 'other solvents' were mainly working in healthcare. The prevalence of occupational exposure to pesticides was low, but was higher among cases than controls (3.6\% versus $2.4 \%$ for chromosomal controls and $2.0 \%$ for non-chromosomal controls). Maternal occupational exposure to organic dust occurred most frequent, with case mothers being more often exposed to organic dust than chromosomal/non-chromosomal controls (36.7\% versus 32.6\%/29.6\%). Mothers exposed to organic dust were working in e.g. healthcare or agriculture.

Table 2 shows the adjusted ORs of maternal occupational exposure. The aORs for maternal occupational exposure to solvents, metals, dust, and gases and fumes did not increase significantly when using chromosomal controls.

When using non-chromosomal controls, aORs increased significantly for maternal occupational exposure to pesticides and dust (Table 3). The highest aORs were found for fungicides and insecticides $(\mathrm{aOR}=2.0,95 \% \mathrm{CI}$ $1.1-3.7$ and aOR $=1.8,95 \%$ CI 1.0-3.2, respectively). The aOR for dust, especially organic dust, increased significantly (aOR $=1.3,95 \%$ CI 1.1-1.7). The significant changes were also observed for organic dust in the $\mathrm{CL}(\mathrm{P})$ group.

Additional analyses with $\mathrm{CL}(\mathrm{P})$ cases were performed stratified by child sex. The aOR for periconceptional exposure to 'other solvents' increased for male infants $(\mathrm{aOR}=1.5,95 \%$ CI 1.1-2.1, data not shown in table $)$ using non-chromosomal controls. The aOR for occupational herbicide exposure in relation to $\mathrm{CL}(\mathrm{P})$ increased for female infants $(\mathrm{aOR}=3.8,95 \%$ CI 1.1-13.4, data not shown in table). However, this was only based on three exposed cases. Mineral dust exposure was associated with $\mathrm{CL}(\mathrm{P})$ for females as well $(\mathrm{aOR}=2.0,95 \% \mathrm{CI} 1.2-$ 3.5 , data not shown in table).

For exposure categories with high prevalence in this study ('other solvents', organic dust, and gases and fumes), additional analyses were performed for all three exposure intensity categories (no, low, and high). The number of high exposed cases was respectively 10, 11, and 4 cases. The aOR for cases with low exposure to 'other solvents' was 1.1 (95\% CI $0.8-1.5)$, and increased to 1.5 (95\% CI $0.8-3.0)$ for cases with high exposure (data not shown in table). For occupational exposure to organic dust the same trend is observed. The aOR increased from 1.3 (95\% CI 1.1-1.6) for low exposure, to 1.7 (95\% CI 0.9-3.2) for high exposure (data not shown in table). No trend of increased is observed OR for occupational exposure to gases and fumes. However, all ORs did not increase significantly. 
Table 2 Prevalence exposures and association between periconceptional maternal occupational exposure and all oral clefts, cleft palate $(C P)$, and cleft lip with/without cleft palate $(C L(P))$ using chromosomal/monogenic controls

\begin{tabular}{|c|c|c|c|c|c|c|c|}
\hline \multirow[t]{2}{*}{ Exposure } & \multirow[t]{2}{*}{ Diagnosis } & \multicolumn{6}{|c|}{ Prevalence exposure } \\
\hline & & $\mathrm{n}$ & $\%$ & OR & $95 \% \mathrm{Cl}$ & $\mathrm{aOR}^{\mathrm{a}}$ & $95 \% \mathrm{Cl}$ \\
\hline \multirow[t]{4}{*}{ Any agent } & Chromosomal control & 465 & 41.0 & Ref & & Ref & \\
\hline & All oral cleft & 170 & 43.9 & 1.1 & $0.9-1.4$ & 1.0 & $0.8-1.3$ \\
\hline & $\mathrm{CP}$ & 42 & 33.9 & 0.7 & $0.5-1.1$ & 0.7 & $0.5-1.1$ \\
\hline & $C L(P)$ & 128 & 48.7 & 1.4 & $1.0-1.8$ & 1.2 & $0.9-1.6$ \\
\hline \multirow[t]{4}{*}{ Solvents } & Chromosomal control & 281 & 24.8 & Ref & & & \\
\hline & All oral cleft & 103 & 26.6 & 1.1 & $0.8-1.4$ & 1.0 & $0.8-1.4$ \\
\hline & $C P$ & 29 & 23.4 & 0.9 & $0.6-1.4$ & 0.9 & $0.6-1.4$ \\
\hline & $C L(P)$ & 74 & 28.1 & 1.2 & $0.9-1.6$ & 1.1 & $0.8-1.5$ \\
\hline \multirow[t]{4}{*}{ Aromatic solvents } & Chromosomal control & 50 & 4.4 & Ref & & Ref & \\
\hline & All oral cleft & 17 & 4.4 & 1.0 & $0.6-1.8$ & 1.1 & $0.6-1.8$ \\
\hline & $C P$ & 5 & 4.0 & 0.9 & $0.4-2.3$ & 1.0 & $0.4-2.6$ \\
\hline & $C L(P)$ & 12 & 4.6 & 1.0 & $0.5-2.0$ & 1.1 & $0.5-2.0$ \\
\hline \multirow[t]{4}{*}{ Chlorinated solvents } & Chromosomal control & 53 & 4.7 & Ref & & Ref & \\
\hline & All oral cleft & 18 & 4.7 & 1.0 & $0.6-1.7$ & 1.0 & $0.5-1.7$ \\
\hline & $\mathrm{CP}$ & 4 & 3.2 & 0.7 & $0.2-1.9$ & 0.7 & $0.2-1.9$ \\
\hline & $C L(P)$ & 14 & 5.3 & 1.1 & $0.6-2.1$ & 1.1 & $0.6-2.0$ \\
\hline \multirow[t]{4}{*}{ Other solvents } & Chromosomal control & 263 & 23.2 & Ref & & Ref & \\
\hline & All oral cleft & 99 & 25.6 & 1.2 & $0.9-1.5$ & 1.1 & $0.8-1.4$ \\
\hline & $C P$ & 28 & 22.6 & 1.0 & $0.6-1.5$ & 0.9 & $0.6-1.5$ \\
\hline & $C L(P)$ & 71 & 27.0 & 1.2 & $0.9-1.7$ & 1.2 & $0.8-1.6$ \\
\hline \multirow[t]{4}{*}{ Pesticides } & Chromosomal control & 27 & 2.4 & Ref & & Ref & \\
\hline & All oral cleft & 14 & 3.6 & 1.5 & $0.8-3.0$ & 1.5 & $0.8-3.0$ \\
\hline & $\mathrm{CP}$ & 5 & 4.0 & 1.7 & $0.7-4.6$ & 1.7 & $0.6-4.6$ \\
\hline & $C L(P)$ & 9 & 3.4 & 1.5 & $0.7-3.1$ & 1.4 & $0.6-3.1$ \\
\hline \multirow[t]{4}{*}{ Fungicides } & Chromosomal control & 23 & 2.0 & Ref & & Ref & \\
\hline & All oral cleft & 13 & 3.4 & 1.7 & $0.8-3.4$ & 1.7 & $0.8-3.5$ \\
\hline & $\mathrm{CP}$ & 5 & 4.0 & 2.0 & $0.8-5.4$ & 2.1 & $0.7-5.7$ \\
\hline & $C L(P)$ & 8 & 3.0 & 1.5 & $0.7-3.4$ & 1.5 & $0.6-3.4$ \\
\hline \multirow[t]{4}{*}{ Herbicides } & Chromosomal control & 15 & 1.3 & Ref & & Ref & \\
\hline & All oral cleft & 6 & 1.6 & 1.2 & $0.5-3.1$ & 1.2 & $0.4-3.1$ \\
\hline & $\mathrm{CP}$ & 1 & 0.8 & 0.6 & $0.1-46$ & 0.6 & $0.1-4.6$ \\
\hline & $C L(P)$ & 5 & 1.9 & 1.4 & $0.5-4.0$ & 1.3 & $0.5-3.9$ \\
\hline \multirow[t]{4}{*}{ Insecticides } & Chromosomal control & 25 & 2.2 & Ref & & Ref & \\
\hline & All oral cleft & 14 & 3.6 & 1.7 & $0.9-3.2$ & 1.7 & $0.8-3.3$ \\
\hline & $\mathrm{CP}$ & 5 & 4.0 & 1.9 & $0.7-5.0$ & 1.8 & $0.7-5.0$ \\
\hline & $C L(P)$ & 9 & 3.4 & 1.6 & $0.7-3.4$ & 1.5 & $0.7-3.3$ \\
\hline \multirow[t]{4}{*}{ Heavy metals } & Chromosomal control & 14 & 1.3 & Ref & & Ref & \\
\hline & All oral cleft & 4 & 1.0 & 0.8 & $0.3-2.6$ & 0.6 & $0.2-2.3$ \\
\hline & $\mathrm{CP}$ & 1 & 0.8 & 0.7 & $0.1-5.0$ & 0.6 & $0.1-5.0$ \\
\hline & $C L(P)$ & 3 & 1.1 & 0.9 & $0.3-3.2$ & 0.8 & $0.2-3.1$ \\
\hline \multirow[t]{2}{*}{ Dust } & Chromosomal control & 385 & 33.9 & Ref & & Ref & \\
\hline & All oral cleft & 146 & 37.7 & 1.2 & $0.9-1.5$ & 1.1 & $0.9-1.4$ \\
\hline
\end{tabular}


Table 2 Prevalence exposures and association between periconceptional maternal occupational exposure and all oral clefts, cleft palate $(C P)$, and cleft lip with/without cleft palate $(C L(P))$ using chromosomal/monogenic controls (Continued)

\begin{tabular}{|c|c|c|c|c|c|c|c|}
\hline & $\mathrm{CP}$ & 37 & 28.8 & 0.8 & $0.5-1.2$ & 0.8 & $0.5-1.2$ \\
\hline & $C L(P)$ & 109 & 41.4 & 1.3 & $0.9-1.7$ & 1.3 & $0.9-1.7$ \\
\hline \multirow[t]{4}{*}{ Organic dust } & Chromosomal control & 370 & 32.6 & Ref & & Ref & \\
\hline & All oral cleft & 142 & 36.7 & 1.2 & $0.9-1.5$ & 1.2 & $0.9-1.4$ \\
\hline & $\mathrm{CP}$ & 36 & 29.0 & 0.8 & $0.6-1.3$ & 0.8 & $0.5-1.2$ \\
\hline & $C L(P)$ & 106 & 40.3 & 1.4 & $1.1-1.8$ & 1.3 & $0.9-1.7$ \\
\hline \multirow[t]{4}{*}{ Mineral dust } & Chromosomal control & 111 & 9.8 & Ref & & Ref & \\
\hline & All oral cleft & 40 & 10.3 & 1.1 & $0.7-1.6$ & 1.1 & $0.7-1.6$ \\
\hline & $\mathrm{CP}$ & 9 & 7.3 & 0.7 & $0.4-1.5$ & 0.8 & $0.4-1.6$ \\
\hline & $C L(P)$ & 31 & 11.8 & 1.2 & $0.8-1.9$ & 1.2 & $0.8-2.0$ \\
\hline \multirow[t]{4}{*}{ Gases and fumes } & Chromosomal control & 353 & 31.1 & Ref & & Ref & \\
\hline & All oral cleft & 126 & 32.6 & 1.1 & $0.8-1.4$ & 1.0 & $0.8-1.3$ \\
\hline & $\mathrm{CP}$ & 29 & 23.4 & 0.7 & $0.4-1.0$ & 0.6 & $0.4-1.0$ \\
\hline & $C L(P)$ & 97 & 36.9 & 1.3 & $1.0-1.7$ & 1.2 & $0.9-1.6$ \\
\hline
\end{tabular}

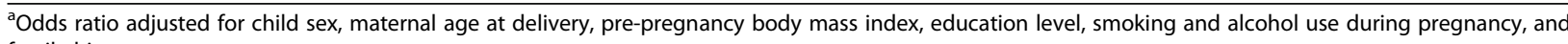
family history

\section{Discussion}

Results from this population-based case-malformed control study indicate an effect for maternal periconceptional occupational exposure to fungicides, insecticides, and organic dust on the risk of oral clefts in the offspring. Male infants have an increased risk on $\mathrm{CL}(\mathrm{P})$ when mothers are occupational exposed to 'other solvents'. Females have an increased on $\mathrm{CL}(\mathrm{P})$ when mothers are exposed to mineral dust. This study shows overall no increased risk of clefts in the offspring when mothers are periconceptionally occupational exposed to solvents, metals, and gases and fumes.

The association between maternal pesticide exposure and oral clefts in the offspring is described previously. A meta-analysis from 2007, that examined the association between occupational exposure to pesticides during pregnancy and oral clefts, showed a significant increased risk of oral clefts $(\mathrm{OR}=1.37,95 \%$ CI 1.041.81) [19]. This is comparable to our study, where we find slightly higher OR of $1.7,95 \%$ CI 1.0-3.1. Most mothers exposed to pesticides in our study were working in agriculture. A Finnish study examined the association between working in agriculture and oral clefts in the offspring [27]. They found a comparable increased OR of oral clefts in the offspring among mothers working in agriculture during the first trimester of their pregnancy $(\mathrm{OR}=1.9,95 \% \mathrm{CI} 1.1-3.5)$.

Furthermore, we observed an association between maternal exposure to dust and oral clefts in the offspring. Despite the fact that occupational exposure to dust is common at the workplace, no studies are known about the relation between occupational dust exposure and congenital anomalies in the offspring.
In our study we found no association between maternal occupational exposure to solvents and oral clefts in the main analyses. However, in the additional analyses an association is found between maternal occupational exposure to 'other solvents' and $\mathrm{CL}(\mathrm{P})$ in male infants only. Our finding is in line with one study from the USA that reported no association [18], but it is in contrast with multiple studies published since 2000 that did report an association between maternal occupational exposure to solvents and oral clefts [10-16]. Most of these studies have been performed in France and the USA and used occupational hygienists, who assessed exposure to specific solvents case-by-case based on detailed standardized interviews in which mothers were asked about job titles and descriptions of the job. The method of classifying occupational exposure by industrial hygienists is more specific and accurate than use of a JEM. However, there is a prospective study, using self-reported exposure assessment as well as a JEM, which reports a significant increased risk of oral clefts in the offspring for mothers exposed to solvents [12]. Inconsistencies could also be due to different definitions of solvent exposure.

We found no significant association between maternal occupational exposure to metals and oral clefts, whereas the study of Hao et al. [21] did find a significant association $(\mathrm{OR}=5.67,95 \%$ CI 1.34-24.09). In our study the prevalence of exposure was very low compared to the Chinese study $(0.8 \%$ in our CP group versus $8.8 \%$ in Hao et al.). No other studies have investigated metal exposure in relation to oral clefts.

Finally, we observed no association between maternal occupational exposure to gases and fumes, which we 
Table 3 Prevalence exposures and association between periconceptional maternal occupational exposure and all oral clefts, cleft palate $(C P)$, and cleft lip with/without cleft palate $(C L(P))$ using non-chromosomal/non-monogenic malformed controls

\begin{tabular}{|c|c|c|c|c|c|c|c|}
\hline \multirow[t]{2}{*}{ Exposure } & \multirow[t]{2}{*}{ Diagnosis } & \multicolumn{6}{|c|}{ Prevalence exposure } \\
\hline & & $\mathrm{n}$ & $\%$ & OR & $95 \% \mathrm{Cl}$ & $\mathrm{aOR}^{\mathrm{a}}$ & $95 \% \mathrm{Cl}$ \\
\hline \multirow[t]{4}{*}{ Any agent } & Non-chromosomal control & 1642 & 37.7 & Ref & & Ref & \\
\hline & All oral cleft & 170 & 43.9 & 1.3 & $1.0-1.6$ & 1.3 & $1.0-1.6$ \\
\hline & $\mathrm{CP}$ & 42 & 33.9 & 0.8 & $0.6-1.2$ & 0.8 & $0.6-1.2$ \\
\hline & $C L(P)$ & 128 & 48.7 & 1.6 & $1.2-2.0$ & 1.5 & $1.2-2.0$ \\
\hline \multirow[t]{4}{*}{ Solvents } & Non-chromosomal control & 1075 & 24.7 & Ref & & & \\
\hline & All oral cleft & 103 & 26.6 & 1.1 & $0.9-1.4$ & 1.1 & $0.9-1.4$ \\
\hline & $C P$ & 29 & 23.4 & 0.9 & $0.6-1.4$ & 0.9 & $0.6-1.4$ \\
\hline & $C L(P)$ & 74 & 28.1 & 1.2 & $0.9-1.6$ & 1.2 & $0.9-1.6$ \\
\hline \multirow[t]{4}{*}{ Aromatic solvents } & Non-chromosomal control & 140 & 3.2 & Ref & & Ref & \\
\hline & All oral cleft & 17 & 4.4 & 1.4 & $0.8-2.3$ & 1.4 & $0.8-2.3$ \\
\hline & $\mathrm{CP}$ & 5 & 4.0 & 1.3 & $0.5-3.1$ & 1.3 & $0.5-3.1$ \\
\hline & $C L(P)$ & 12 & 4.6 & 1.4 & $0.8-2.6$ & 1.5 & $0.8-2.7$ \\
\hline \multirow[t]{4}{*}{ Chlorinated solvents } & Non-chromosomal control & 190 & 4.4 & Ref & & Ref & \\
\hline & All oral cleft & 18 & 4.7 & 1.1 & $0.7-1.8$ & 1.1 & $0.7-1.8$ \\
\hline & $C P$ & 4 & 3.2 & 0.7 & $0.3-2.0$ & 0.7 & $0.3-2.0$ \\
\hline & $C L(P)$ & 14 & 5.3 & 1.2 & $0.7-2.2$ & 1.3 & $0.7-2.2$ \\
\hline \multirow[t]{4}{*}{ Other solvents } & Non-chromosomal control & 1042 & 23.9 & Ref & & Ref & \\
\hline & All oral cleft & 99 & 25.6 & 1.1 & $0.9-1.4$ & 1.1 & $0.9-1.4$ \\
\hline & $C P$ & 28 & 22.6 & 0.9 & $0.6-1.4$ & 0.9 & $0.6-1.4$ \\
\hline & $C L(P)$ & 71 & 27.0 & 1.2 & $0.9-1.6$ & 1.2 & $0.9-1.6$ \\
\hline \multirow[t]{4}{*}{ Pesticides } & Non-chromosomal control & 88 & 2.0 & Ref & & Ref & \\
\hline & All oral cleft & 14 & 3.6 & 1.8 & $1.0-3.2$ & 1.7 & $1.0-3.1$ \\
\hline & $\mathrm{CP}$ & 5 & 4.0 & 2.0 & $0.8-5.1$ & 1.9 & $0.8-4.8$ \\
\hline & $C L(P)$ & 9 & 3.4 & 1.7 & $0.9-3.4$ & 1.7 & $0.8-3.4$ \\
\hline \multirow[t]{4}{*}{ Fungicides } & Non-chromosomal control & 70 & 1.6 & Ref & & Ref & \\
\hline & All oral cleft & 13 & 3.4 & 2.1 & $1.2-3.9$ & 2.0 & $1.1-3.7$ \\
\hline & $C P$ & 5 & 4.0 & 2.6 & $1.0-6.5$ & 2.4 & $0.9-6.0$ \\
\hline & $C L(P)$ & 8 & 3.0 & 1.8 & $0.9-3.6$ & 1.9 & $0.9-4.0$ \\
\hline \multirow[t]{4}{*}{ Herbicides } & Non-chromosomal control & 36 & 0.8 & Ref & & Ref & \\
\hline & All oral cleft & 6 & 1.6 & 1.9 & $0.8-4.5$ & 1.8 & $0.8-4.4$ \\
\hline & $C P$ & 1 & 0.8 & 1.0 & $0.1-72$ & 0.9 & $0.1-7.0$ \\
\hline & $C L(P)$ & 5 & 1.9 & 2.3 & $0.9-6.0$ & 2.3 & $0.9-5.9$ \\
\hline \multirow[t]{4}{*}{ Insecticides } & Non-chromosomal control & 84 & 1.9 & Ref & & Ref & \\
\hline & All oral cleft & 14 & 3.6 & 1.9 & $1.1-3.4$ & 1.8 & $1.0-3.2$ \\
\hline & $\mathrm{CP}$ & 5 & 4.0 & 2.1 & $0.9-5.4$ & 2.0 & $0.8-5.0$ \\
\hline & $C L(P)$ & 9 & 3.4 & 1.8 & $0.9-3.6$ & 1.7 & $0.9-3.5$ \\
\hline \multirow[t]{4}{*}{ Heavy metals } & Non-chromosomal control & 44 & 1.0 & Ref & & Ref & \\
\hline & All oral cleft & 4 & 1.0 & 1.0 & $0.4-2.9$ & 1.1 & $0.4-3.0$ \\
\hline & $C P$ & 1 & 0.8 & 0.8 & $0.1-5.8$ & 0.9 & $0.1-6.3$ \\
\hline & $C L(P)$ & 3 & 1.1 & 1.1 & $0.3-3.7$ & 1.2 & $0.4-3.8$ \\
\hline \multirow[t]{2}{*}{ Dust } & Control & 1346 & 30.9 & Ref & & Ref & \\
\hline & All oral cleft & 146 & 37.7 & 1.4 & $1.1-1.7$ & 1.3 & $1.1-1.6$ \\
\hline
\end{tabular}


Table 3 Prevalence exposures and association between periconceptional maternal occupational exposure and all oral clefts, cleft palate (CP), and cleft lip with/without cleft palate (CL(P)) using non-chromosomal/non-monogenic malformed controls (Continued)

\begin{tabular}{|c|c|c|c|c|c|c|c|}
\hline & $\mathrm{CP}$ & 37 & 28.8 & 1.0 & $0.6-1.4$ & 0.9 & $0.6-1.4$ \\
\hline & $C L(P)$ & 109 & 41.4 & 1.6 & $1.2-2.0$ & 1.5 & $1.2-2.0$ \\
\hline \multirow[t]{4}{*}{ Organic dust } & Non-chromosomal control & 1288 & 29.6 & Ref & & Ref & \\
\hline & All oral cleft & 142 & 36.7 & 1.4 & $1.1-1.7$ & 1.3 & $1.1-1.7$ \\
\hline & $\mathrm{CP}$ & 36 & 29.0 & 1.0 & $0.7-1.4$ & 1.0 & $0.6-1.4$ \\
\hline & $C L(P)$ & 106 & 40.3 & 1.6 & $1.2-2.1$ & 1.6 & $1.2-2.0$ \\
\hline \multirow[t]{4}{*}{ Mineral dust } & Non-chromosomal control & 396 & 9.1 & Ref & & Ref & \\
\hline & All oral cleft & 40 & 10.3 & 1.2 & $0.8-1.6$ & 1.1 & $0.8-1.6$ \\
\hline & $\mathrm{CP}$ & 9 & 7.3 & 0.8 & $0.4-1.6$ & 0.8 & $0.4-1.5$ \\
\hline & $C L(P)$ & 31 & 11.8 & 1.3 & $0.9-2.0$ & 1.3 & $0.9-1.9$ \\
\hline \multirow[t]{4}{*}{ Gases and fumes } & Non-chromosomal control & 1521 & 34.9 & Ref & & Ref & \\
\hline & All oral cleft & 126 & 32.6 & 0.8 & $0.7-1.1$ & 0.9 & $0.7-1.1$ \\
\hline & $\mathrm{CP}$ & 29 & 23.4 & 0.6 & $0.4-0.9$ & 0.6 & $0.4-0.9$ \\
\hline & $C L(P)$ & 97 & 36.9 & 1.1 & $0.8-1.4$ & 1.1 & $0.8-1.4$ \\
\hline
\end{tabular}

Odds ratio adjusted for child sex, and previous births. Bold values represent significant values

analysed because these are often co-exposures in women exposed to pesticides, solvents and metals.

\section{Strengths and limitations}

A major strength of this study is the use of data from the population-based Eurocat registry. Ascertainment of oral cleft cases by Eurocat NNL was virtually complete for birth years 1997-2009, with a consent rate for registration of over 90\% [8].Data in the Eurocat NNL database are of high quality and congenital anomalies are classified according to high standards and ICD codes. This made it possible to accurately distinguish between isolated clefts, clefts occurring together with other major congenital anomalies and syndromic clefts. Moreover, because both cases and both control groups had anomalies, recall bias is not expected to play a role in our study design.

Another strength is the use of the ALOHA+ JEM. The benefit of using a JEM is that it avoids recall bias since the mother is not directly asked about her occupational exposure during pregnancy. Besides, results in occupational exposure estimates are that are less prone to differential misclassification of exposure compared to selfreported exposures [24, 28].

The Eurocat NNL questionnaire includes questions about job title and workplace during pregnancy, but did not include questions about the actual job tasks that were performed. It is therefore possible that women avoided certain activities during the periconceptional period in order to decrease exposure to potential teratogenic agents. Their actual exposure could therefore have been lower or absent from what was assigned by the JEM based on their job. Another limitation of using a JEM, compared to expert assessment, is that JEMs have often low sensitivity. Partly, this low sensitivity is due to the variability in exposure across time which is not taken into account by the JEM [29].

In our study a relatively low numbers of cases are exposed to pesticides. This has resulted in a lower power. Besides, our study could not address exposure intensity for all subcategories of exposure as assigned by the JEM (low or high exposure) separately in our analyses, due to the low numbers of highly exposed women. This precluded an exposure-response evaluation.

Finally, we used malformed controls and could therefore not compare with healthy children. It is known that occupational exposure to pesticides is possibly associated with chromosomal aberrations [30]. Furthermore, residential exposure to solvents or metals has been suggested to be associated with an increased risk of chromosomal anomalies in the offspring of older women [31]. Given our design, if these associations between occupational exposure and chromosomal anomalies would have been present, this would have resulted in attenuated risk estimates of maternal occupational exposures for the risk of oral clefts in the offspring.

\section{Conclusion}

Our study indicates that maternal periconceptional occupational exposure to pesticides and dust are risk factors for oral clefts, in particular exposure to fungicides, insecticides and organic dust is associated with an increased risk for cleft palate in the offspring. Occupational maternal exposure to 'other solvents' gives an increased risk of CL(P) in male offspring, whereas mineral dust is associated with $\mathrm{CL}(\mathrm{P})$ in female offspring. Exposure to solvents, metals, and gases and fumes are not shown to be associated with 
oral clefts in the offspring. More data are needed to identify whether the association between periconceptional occupational maternal solvents, pesticides, and dust exposure and cleft palate in the offspring is causal.

\section{Abbreviations}

aOR: Adjusted odds ratio; BMI: Body mass index; Cl: Confidence interval; $\mathrm{CL}(\mathrm{P})$ : Cleft lip with or without palate; CP: Cleft palate; Eurocat NNL: European Registration of Congenital Anomalies and Twins database of the Northern Netherlands; JEM: Job Exposure Matrix; OR: Odds ratio

\section{Acknowledgements}

We thank all those who are involved in providing and processing information including the affected families, clinicians, health professionals, medical record clerks, and registry staff. We thank Nicole Siemensma for help with the EUROCAT Northern Netherlands database, Jackie Senior and Kate Mc Intyre for editorial assistance.

\section{Funding}

EUROCAT Northern Netherlands is funded by the Dutch Ministry of Welfare, Health and Sports. The funder had no role in study design, data collection, data analysis, data interpretation, or writing of the report. The corresponding author had full access to all the data in this study.

\section{Availability of data and materials}

The data that support the findings of this study are available from the corresponding author upon reasonable request.

\section{Authors' contributions}

NS participated in the study design, analysis and interpretation of the data and drafting of the manuscript and Tables. NS and HK coded the occupational information. HK and RV designed and provided the ALOHA+ JEM. JEHB, HMB, HK and HEKdW determined the study design, participated in the analysis and interpretation of data and critically supervised writing of the manuscript. All authors approved the final version of the manuscript

\section{Ethics approval and consent to participate}

Eurocat data were collected with written informed consent of the parents. Studies using data from these health registries do not require ethical approval in the Netherlands. The principles outlined in the declaration of Helsinki were followed.

\section{Consent for publication}

Not applicable.

\section{Competing interests}

The authors declare that they have no competing interests.

\section{Publisher's Note}

Springer Nature remains neutral with regard to jurisdictional claims in published maps and institutional affiliations.

\footnotetext{
Author details

${ }^{1}$ Department of Epidemiology, University of Groningen, University Medical Center Groningen, HPC FA 40, P.O. Box 30.001, 9700 RB Groningen, the Netherlands. ${ }^{2}$ Department of Genetics, University of Groningen, University Medical Center Groningen, HPC CB 51, P.O. Box 30.001, 9700 RB Groningen, the Netherlands. ${ }^{3}$ Division of Environmental Epidemiology, Institute for Risk Assessment Science, Utrecht University, Postbox 80178, 3508 TD Utrecht, the Netherlands.
}

Received: 13 October 2016 Accepted: 1 August 2017 Published online: 04 August 2017

\section{References}

1. Eurocat NNL. Update: actual numbers of congenital anomalies 2013 (update: actuele cijfers aangeboren aandoeningen 2013). Available at: http://www.rug.nl/research/genetics/eurocat/algemene-cijfers-tabel-2013final.pdf. Accessed 5 July 2015.
2. Nidey N, Moreno Uribe LM, Marazita MM, Wehby GL. Psychosocial wellbeing of parents of children with oral clefts. Child Care Health Dev. 2015; 42(1):42-50.

3. Leite M, Albieri V, Kjaer SK, Jensen A. Maternal smoking in pregnancy and risk for congenital malformations: results of a Danish register-based cohort study. Acta Obstet Gynecol Scand. 2014;93(8):825-34

4. Romitti PA, Sun L, Honein MA, Reefhuis J, Correa A, Rasmussen SA. Maternal periconceptional alcohol consumption and risk of orofacial clefts. Am J Epidemiol. 2007;166(7):775-85.

5. Rankin J, Tennant PWG, Stothard KJ, Bythell M, Summerbell CD, Bell R. Maternal body mass index and congenital anomaly risk: a cohort study. Int J Obes. 2010;34:1371-80.

6. Stothard KJ, Tennant PW, Bell R, Rankin J. Maternal overweight and obesity and the risk of congenital anomalies: a systematic review and meta-analysis. JAMA. 2009:301(6):636-50.

7. Kutbi H, Wehby GL, Moreno Uribe LM, Romitti PA, Carmichael S, Shaw GM, et al. Maternal underweight and obesity and risk of orofacial clefts in a large international consortium of population-based studies. Int J Epidemiol. 2016:1-10.

8. Rozendaal AM, van Essen AJ, te Meerman GJ, Bakker MK, van der Biezen JJ, Goorhuis-Brouwer SM, et al. Periconceptional folic acid associated with an increased risk of oral clefts relative to non-folate related malformations in the Northern Netherlands: a population based case-control study. Eur J Epidemiol. 2013;28(11):875-87.

9. Statistics Netherlands. Female labour participation stabilising following years of increase. Available at: http://www.cbs.nl/en-GB/menu/themas/dossiers/ vrouwen-en-mannen/publicaties/artikelen/archief/2014/2014-4196-wm.htm. Accessed 23 Sept 2015.

10. Desrosiers TA, Lawson CC, Meyer RE, Richardson DB, Daniels JL, Waters MA, et al. Maternal occupational exposure to organic solvents during early pregnancy and risks of neural tube defects and orofacial clefts. Occup Environ Med. 2012;69(7):493-9.

11. Langlois PH, Hoyt AT, Lupo PJ, Lawson CC, Waters MA, Desrosiers TA, et al. Maternal occupational exposure to polycyclic aromatic hydrocarbons and risk of oral cleft-affected pregnancies. Cleft Palate Craniofac J. 2013:50(3):337-46.

12. Garlantezec R, Monfort C, Rouget F, Cordier S. Maternal occupational exposure to solvents and congenital malformations: a prospective study in the general population. Occup Environ Med. 2009;66(7):456-63.

13. Lorente C, Cordier S, Bergeret A, De Walle HE, Goujard J, Ayme S, et al. Maternal occupational risk factors for oral clefts. Occupational Exposure and Congenital Malformation Working Group. Scand J Work Environ Health. 2000;26(2):137-45

14. Chevrier C, Dananché B, Bahuau M, Nelva A, Herman C, Francannet C, et al. Occupational exposure to organic solvent mixtures during pregnancy and the risk of non-syndromic oral clefts. Occup Environ Med. 2006;63(9):617-23.

15. Cordier S, Garlantezec R, Labat L, Rouget F, Monfort C, Bonvallot N, et al. Exposure during pregnancy to glycol ethers and chlorinated solvents and the risk of congenital malformations. Epidemiology. 2012;23(6):806-12.

16. Laumon B, Martin JL, Collet P, Bertucat I, Verney MP, Robert E. Exposure to organic solvents during pregnancy and oral clefts: a case-control study. Reprod Toxicol. 1996;10(1):15-9.

17. Holmberg PC, Hernberg S, Kurppa K, Rantala K, Riala R. Oral clefts and organic solvent exposure during pregnancy. Int Arch Occup Environ Health. 1982;50:371.

18. Shaw GM, Nelson V, lovannisci DM, Finnell RH, Lammer EJ. Maternal occupational chemical exposures and biotransformation genotypes as risk factors for selected congenital anomalies. Am J Epidemiol. 2003:157(6):475-84.

19. Romitti PA, Herring AM, Dennis LK, Wong-Gibbons DL. Meta-analysis: pesticides and orofacial clefts. Cleft Palate Craniofac J. 2007:44(4):358-65.

20. Yang W, Carmichael SL, Roberts EM, Kegley SE, Padula AM, English PB, et al. Residential agricultural pesticide exposures and risk of neural tube defects and orofacial clefts among offspring in the San Joaquin Valley of California. Am J Epidemiol. 2014;179(6):740-8.

21. Hao Y, Tian S, Jiao X, Mi N, Zhang B, Song T, et al. Association of Parental Environmental Exposures and Supplementation Intake with Risk of Nonsyndromic Orofacial Clefts: A Case-control Study in Heilongjiang Province, China. Nutrients. 2015;7(9):7172-84.

22. Greenlees R, Neville A, Addor MC, Amar E, Arriola L, Bakker M, et al. Paper 6: EUROCAT member registries: organization and activities. Birth Defects Res A Clin Mol Teratol. 2011:91(Suppl 1):S51-S100

23. Matheson MC, Benke G, Raven J, Sim MR, Kromhout H, Vermeulen R, et al. Biological dust exposure in the workplace is a risk factor for chronic obstructive pulmonary disease. Thorax. 2005;60(8):645-51. 
24. Kromhout $\mathrm{H}$, Vermeulen R. Application of job-exposure matrices in studies of the general population: some clues to their performance. Eur Respir Rev. 2001;11:80-90

25. International Labor Office. International Standard Classification of Occupations. 1988

26. Health Council of the Netherlands. Towards an optimal use of folic acid. 2008, 2008/02E(06/01)

27. Nurminen T, Rantala K, Kurppa K, Holmberg PC. Agricultural Work during Pregnancy and Selected Structural Malformations in Finland. Epidemiology. 1995;6(1):23-30.

28. Mannetje $\mathrm{A}$, Kromhout $\mathrm{H}$. The use of occupation and industry classifications in general population studies. Int J Epidemiol. 2003;32(3):419-28.

29. Teschke K, Olshan AF, Daniels JL, De Roos AJ, Parks CG, Schulz M. Occupational exposure assessment in case-control studies: opportunities for improvement. Occup Environ Med. 2002:59(9):575-93. discussion 594

30. Bolognesi C. Genotoxicity of pesticides: a review of human biomonitoring studies. Mutat Res. 2003;543(3):251-72.

31. Brender JD, Zhan FB, Langlois PH, Suarez L, Scheuerle A. Residential proximity to waste sites and industrial facilities and chromosomal anomalies in offspring. Int J Hyg Environ Health. 2008;211(1-2):50-8.

Submit your next manuscript to BioMed Central and we will help you at every step:

- We accept pre-submission inquiries

- Our selector tool helps you to find the most relevant journal

- We provide round the clock customer support

- Convenient online submission

- Thorough peer review

- Inclusion in PubMed and all major indexing services

- Maximum visibility for your research

Submit your manuscript at www.biomedcentral.com/submit
Biomed Central 